\title{
Understanding Dengue Control for Short- and Long-Term Intervention with a Mathematical Model Approach
}

\author{
A. Bustamam, D. Aldila $(\mathbb{D}$, and A. Yuwanda \\ Department of Mathematics, Universitas Indonesia, Depok 16424, Indonesia \\ Correspondence should be addressed to D. Aldila; aldiladipo@sci.ui.ac.id
}

Received 10 August 2017; Accepted 19 November 2017; Published 1 January 2018

Academic Editor: Lucas Jodar

Copyright (c) 2018 A. Bustamam et al. This is an open access article distributed under the Creative Commons Attribution License, which permits unrestricted use, distribution, and reproduction in any medium, provided the original work is properly cited.

\begin{abstract}
A mathematical model of dengue diseases transmission will be discussed in this paper. Various interventions, such as vaccination of adults and newborns, the use of insecticides or fumigation, and also the enforcement of mechanical controls, will be considered when analyzing the best intervention for controlling the spread of dengue. From model analysis, we find three types of equilibrium points which will be built upon the dengue model. In this paper, these points are the mosquito-free equilibrium, disease-free equilibrium (with and without vaccinated compartment), and endemic equilibrium. Basic reproduction number as an endemic indicator has been found analytically. Based on analytical and numerical analysis, insecticide treatment, adult vaccine, and enforcement of mechanical control are the most significant interventions in reducing the spread of dengue disease infection caused by mosquitoes rather than larvicide treatment and vaccination of newborns. From short- and long-term simulation, we find that insecticide treatment is the best strategy to control dengue. We also find that, with periodic intervention, the result is not much significantly different with constant intervention based on reduced number of the infected human population. Therefore, with budget limitations, periodic intervention of insecticide strategy is a good alternative to reduce the spread of dengue.
\end{abstract}

\section{Introduction}

Dengue is the most rapidly growing disease in the world [1]. The disease is spread by Aedes mosquitoes and is therefore often referred to as a mosquito-borne viral disease. The disease has become endemic in more than 100 countries, including the Caribbean, Africa, the Americas, the Pacific, and Asia, including Indonesia [1]. As an endemic disease, dengue occurs regularly in subtropical and tropical regions of the world, and approximately $40 \%$ of people live in regions of the world where there is a risk of contracting it [2]. Dengue is a vector-borne disease transmitted from an infected human to a female Aedes aegypti mosquito by a bite. The mosquito, which needs regular meals of blood to mature its eggs, completes the cycle by biting a healthy human, transmitting the disease in one act [3].

Until now, the primary prevention for dengue has been control of mosquitoes, in both larval and adult forms. Larval control is carried out by larvicide treatment using longlasting chemicals to kill larvae, which sure preferably have WHO clearance for use in drinking water [4]. Mechanical controls are also used to control larvae, with assistance from campaigns and educational programs carried out by governments. In Indonesia, such a program is known as $3 \mathrm{M}$ and consists of educating people about the importance of draining and shutting down and burying all tubs, buckets, or containers of water that which be used by female mosquitoes to breed and lay their eggs [5]. The larvae of Aedes aegypti can also grow in used goods that can hold water, and it is therefore recommended to make sure the environment around the house has no space that could allow mosquitoes to breed.

Adult mosquito control is achieved by the use of insecticide. Insecticide fumigation targets the vector Aedes aegypti mosquito as the main control of dengue epidemics. However, the long-term use of insecticides and larvicides poses several risks: one is resistance of the mosquito to the product, reducing its efficacy, while genetic mutation of the mosquito, making it less susceptible to the effects of the product, is another. Such products have also been linked to numerous adverse health effects including the worsening of asthma and respiratory problems $[3,6]$. In Surabaya, Indonesia, larval mortality rates of under $80 \%$ indicate possible resistance of 
Aedes aegypti to the insecticide temephos [7], and outside Indonesia, resistance to insecticide has been reported in multiple countries. In recent years, the frequency of $\mathrm{kdr}$ mutations associated with pyrethroid resistance has increased rapidly [8]. Pyrethroids have become the most frequently used public health insecticides globally due to their low cost and low toxicity to mammals [9], and they are of considerable concern when $\mathrm{kdr}$ is found in wild populations of vector mosquitoes [8]. With the many cases of Aedes aegypti mosquito's resistance to insecticide, it is therefore necessary to develop alternative strategies to slow its evolution.

Besides controlling dengue via control of mosquitoes population, one of the alternative strategies that is being used is dengue vaccine. In December 2015, the first vaccine against dengue by Sanofi Pasteur, Dengvaxia (CYD-TDV), was approved in three highly endemic countries: Mexico, Philippines, and Brazil [10]. This vaccine is the world's first dengue vaccine and is already licensed for individuals aged 9-45 years for the prevention of infectious disease caused by four dengue virus serotypes (DEN 1, DEN 2, DEN 3, and DEN 4) [11]. In Indonesia, so far, the government is still conducting clinical trials to determine its effectiveness. However, assessments of the public's acceptance of the dengue vaccine and its associated factors are widely lacking [12]. A lack of understanding about the importance of vaccination against dengue to the public will be able to reduce the success rate of vaccination interventions in various countries, especially in a country that is less intensive to educate people about the importance of dengue fever vaccination [13]. In 2017, Dengvaxia would have been applied if proven effective and suitable for the dengue serotypes which are pandemic in Indonesia [14].

The earliest mathematical models for dengue disease transmission are developed in $[15,16]$ which are closely related to the models for the transmission of malaria discussed in $[17,18]$. The authors in [16] create the model for two types of viruses by allowing temporary cross immunity and increased susceptibility to the second infection due to the first infection. The intervention has not yet been used into the mathematical model [16]. In [19], the mathematical model with only insecticide campaign intervention is discussed. It has been shown that, with a steady insecticide campaign, it is possible to reduce the number of infected humans and mosquitoes and prevent an outbreak that could transform an epidemiological episode to an endemic disease [19]. A year after the research discussed in [19], it was updated [20], and the mathematical model for dengue was updated continuously with all controls included, that is, (1) proportion of larvicide, (2) proportion of adulticide, and (3) proportion of mechanical control. The results have shown that, even with a low, although continuous, index of control adulticide over time, the results are surprisingly positive [20]. However, it has been stated that to rely only on adulticide is a risky decision [20]. The research in $[6,7,21]$ supports this claim, citing the problem of Aedes aegypti mosquito's resistance to insecticide. Under the new achievement in the field of vaccination technology with the discovery of the first vaccine against dengue by Sanofi Pasteur, the work in [22] devised two models, one assuming that unintentional vaccination increases the infectious period and another assuming that unintentional vaccination leads to the development of symptoms. This argument is also supported by [3], in which the mathematical model is created with the vaccine as the new compartment, arguing that the vaccine must divide the human population into classes, that is, the perfect pediatric vaccine for newborns and perfect adult vaccine (conferring $100 \%$ protection throughout life), and also classes of human with imperfect vaccine effect [3]. Other mathematical models with different intervention were also introduced in [23] which discuss the use of mosquito repellent to reduce probability of success of infection in human population and in [4] which discuss the use of sterile mosquito strategy.

According to above explanation, it is important to find the best strategy for controlling dengue spreads for both shortterm and long-term interventions. Therefore, a mathematical model of dengue disease transmission by using adult and newborn vaccines with waning immunity, the use of insecticides and larvicides, and mechanical control will be developed in the next section. Equilibrium points will be found, which ensure the existence of local stability. Basic reproduction numbers will be obtained as the main factor in whether the disease will become epidemic in a population or not. Numerical analysis for comparing the dynamic of infected humans and mosquitoes will be used to support the model interpretation.

\section{Mathematical Model Construction}

To construct our model, firstly we divide the human population into four compartments, that is,

$S_{h}(t)$ : susceptible (individuals who can be infected with dengue);

$V_{h}(t)$ : vaccinated (individuals who have had the vaccine injected into their bodies, making them resistant to infectious disease. However, the use of the vaccine does not provide perfect immunity. There will be a time when the vaccine does not work properly in the body or when the effect of the vaccine has begun to subside [3]);

$\operatorname{In}_{h}(t)$ : infected (individuals who are infected with dengue. In this case, the infected human is incapable of transmitting the disease to other humans);

$R_{h}(t)$ : recovered (individuals who have recovered from dengue and have acquired temporal immunity to respective DEN virus).

On the other hand, we divide the mosquito population into three compartments, that is,

$A_{v}(t)$ : aquatic phase (the phase that includes the egg, larvae, and pupa stages, which live in water);

$S_{v}(t)$ : susceptible (mosquitoes that are able to infect with dengue);

$\operatorname{In}_{v}(t)$ : infected (mosquitoes that have been infected with dengue by an infected human and are capable of transmitting dengue to humans). 


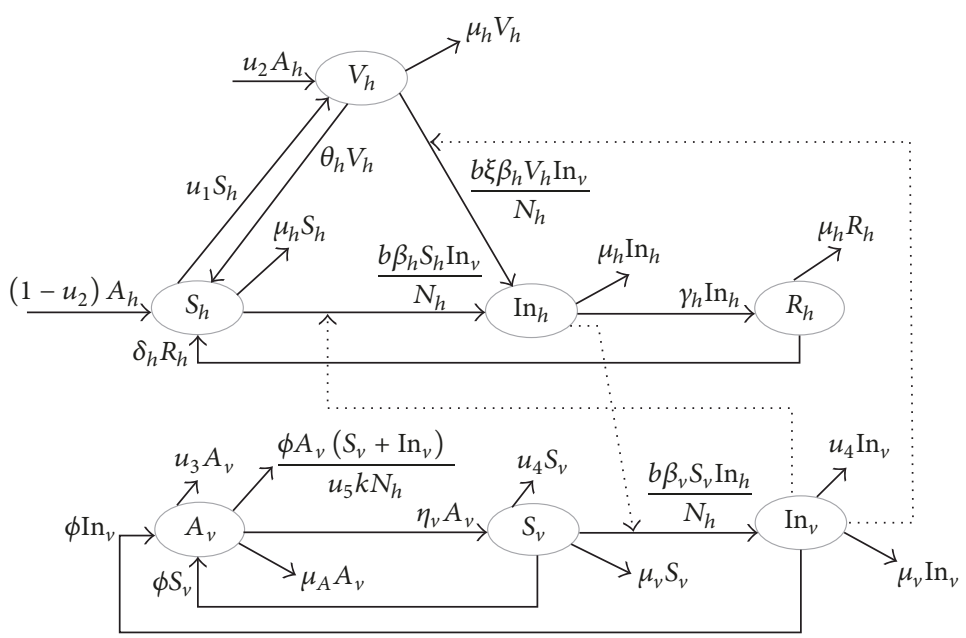

Figure 1: Mathematical model using vaccination of adults and newborns, fumigation and larvicide treatment, and enforcement of mechanical control.

Secondly, we have made some assumptions that we will use to describe a dynamic process in our model that we will construct: (1) There is no migration in either human or mosquito population. (2) Humans and mosquitoes are assumed to be born susceptible, there is no natural protection, and dengue is not passed onto the next generation (no vertical transmission) [19]. (3) The transmission process in susceptible and vaccinated humans is simply by the bite of an infected mosquito. Infected humans cannot transmit the virus to other susceptible or vaccinated humans [19]. (4) The death rate is considered to be a natural death rate in both populations. (5) Vaccinated human status is considered temporary because of the ability of the vaccine to subside over time [3]. (6) There is no recovered phase in mosquitoes due to their short lifespan [20]. (7) There is no resistant (immune) effect in mosquitoes to the use of synthetic fumigation, such as insecticides and larvicides [6, 7]; in this article, we assume that there is no resistant (immunity) effect to mosquitoes due to use of synthetic fumigation, such as insecticide and larvicide.

With the assumptions, variables, and transmission diagram given in Figure 1, the model is represented as a sevendimensional system of differential equations which are given by

$$
\begin{aligned}
\frac{d S_{h}}{d t}= & \left(1-u_{2}\right) A_{h}-\frac{b \beta_{h} S_{h} \operatorname{In}_{v}}{N_{h}}-u_{1} S_{h}-\mu_{h} S_{h}+\delta_{h} R_{h} \\
& +\theta_{h} V_{h}, \\
\frac{d V_{h}}{d t}= & u_{2} A_{h}+u_{1} S_{h}-\frac{b \xi \beta_{h} V_{h} \operatorname{In}_{v}}{N_{h}}-\mu_{h} V_{h}-\theta_{h} V_{h}, \\
\frac{d \operatorname{In}_{h}}{d t}= & \frac{b \beta_{h} \operatorname{In}_{v}\left(S_{h}+\xi V_{h}\right)}{N_{h}}-\gamma_{h} \operatorname{In}_{h}-\mu_{h} \operatorname{In}_{h}, \\
\frac{d R_{h}}{d t}= & \gamma_{h} \operatorname{In}_{h}-\mu_{h} R_{h}-\delta_{h} R_{h},
\end{aligned}
$$

$$
\begin{aligned}
\frac{d A_{v}}{d t}= & \phi\left(1-\frac{A_{v}}{u_{5} k N_{h}}\right)\left(S_{v}+\operatorname{In}_{v}\right)-u_{3} A_{v}-\eta_{v} A_{v} \\
& -\mu_{A} A_{v}, \\
\frac{d S_{v}}{d t}= & \eta_{v} A_{v}-\frac{b \beta_{v} S_{v} \operatorname{In}_{h}}{N_{h}}-\mu_{v} S_{v}-u_{4} S_{v}, \\
\frac{d \operatorname{In}_{v}}{d t}= & \frac{b \beta_{v} S_{v} \operatorname{In}_{h}}{N_{h}}-\mu_{v} \operatorname{In}_{v}-u_{4} \operatorname{In}_{v},
\end{aligned}
$$

with parameters description being the following:

$$
N_{h} \text { : total of human population }
$$

$A_{h}$ : human per capita birth rate

$b$ : average number of bites of humans by mosquitoes

$\beta_{h}$ : average of successful transmission in human

$\beta_{v}$ : average of successful transmission in mosquitoes

$\mu_{h}$ : human death rate

$\mu_{v}$ : mosquito death rate

$\mu_{A}$ : larval death rate

$\delta_{h}$ : the rate of change from $R_{h}$ to $S_{h}$ because of the disappearance of the temporal natural immunity

$\theta_{h}$ : the rate of change from $V_{h}$ to $S_{h}$ because of the disappearance of the temporal vaccine effect

$\xi$ : reduction of $\beta_{h}$ because of vaccine

$\gamma_{h}$ : human recovery rate

$\phi$ : average number of eggs at each deposit

$k$ : ratio for number of larvae per human

$\eta_{v}$ : transition rate from $A_{v}$ to $S_{v}$

$u_{1}$ : adult vaccination rate

$u_{2}$ : newborn vaccine 
$u_{3}$ : larvicide rate

$u_{4}$ : fumigation rate

$u_{5}$ : enforcement of mechanical control proportion to reduce $k$

In the next section, mathematical model analysis to find equilibrium points and their local stability criteria will be given.

\section{Equilibrium Points and Local Stability}

From the system of equation (1), we find three types of equilibrium points.

3.1. Mosquito-Free Equilibrium (MFE) Point. It is the equilibrium where the mosquito virus does not exist in the living environment, so any infectious disease never occurs at the MFE point (sterile conditions). This equilibrium is given by

$$
\begin{aligned}
S_{h}^{1} & =-\frac{A_{h}\left(\mu_{h}+\theta_{h}\right)\left(R_{2}-1\right)}{\mu_{h}\left(\mu_{h}+u_{1}+\theta_{h}\right)}, \\
V_{h}^{1} & =\frac{A_{h}\left(\mu_{h} u_{2}+u_{1}\right)}{\mu_{h}\left(\mu_{h}+u_{1}+\theta_{h}\right)} \\
\operatorname{In}_{h}^{1} & =0 \\
R_{h}^{1} & =0 \\
A_{v}^{1} & =0 \\
S_{v}^{1} & =0 \\
\operatorname{In}_{v}^{1} & =0 .
\end{aligned}
$$

At the MFE point, it can be seen that $S_{h}^{1}$ can have either a positive or a negative value. However, from an epidemiological point of view, a population has biological meaning only if it has a nonnegative value. Therefore, to ensure that the MFE point exists, the positiveness for $S_{h}^{1}$ should be made; that is,

$$
R_{2}=\frac{\mu_{h} u_{2}}{\mu_{h}+\theta_{h}}<1
$$

To guarantee local stability of equilibrium, it is necessary to ensure that all eigenvalues of system (1) in its Jacobian matrix evaluated in the MFE have negative values. The condition is

$$
\frac{\eta_{v} \phi}{\left(\mu_{v}+u_{4}\right)\left(u_{3}+\eta_{v}+\mu_{A}\right)}=R_{1}<1 .
$$

Please note that $R_{1}$ is known as the basic offspring number, which will guarantee the existence of mosquitoes in the population. The mosquito population will exist if, and only if, $R_{1} \geq 1$ as will be discussed in the next equilibrium point.

3.2. Disease-Free Equilibrium (DFE) Point. DFE is an equilibrium where mosquito and human populations exist in the living environment, but the virus does not occur.
We have two types of DFE equilibrium point, which are DFE-1 and DFE-2. DFE-1 describes a condition where infected, recovered human groups and infected, recovered mosquito groups do not exist, while DFE-2 describes a condition where infected, recovered human groups, infected, recovered mosquito groups, and human vaccinated groups do not exist (special case without intervention of vaccines $\left.\left(u_{1}=u_{2}=0\right)\right)$.

3.2.1. Disease-Free Equilibrium I (DFE-1) Point. This equilibrium is given by

$$
\begin{aligned}
S_{h}^{2} & =-\frac{A_{h}\left(\mu_{h}+\theta_{h}\right)\left(R_{2}-1\right)}{\mu_{h}\left(\mu_{h}+u_{1}+\theta_{h}\right)}, \\
V_{h}^{2} & =\frac{A_{h}\left(\mu_{h} u_{2}+u_{1}\right)}{\mu_{h}\left(\mu_{h}+u_{1}+\theta_{h}\right)}, \\
\operatorname{In}_{h}^{2} & =0, \\
R_{h}^{2} & =0, \\
A_{v}^{2} & =u_{5} k N_{h}\left(R_{1}-1\right), \\
S_{v}^{2} & =\frac{u_{5} k N_{h} \eta_{v}\left(R_{1}-1\right)}{\mu_{v}+u_{4}}, \\
\operatorname{In}_{v}^{2} & =0
\end{aligned}
$$

which will exist if and only if

$$
\begin{aligned}
& R_{1}=\frac{\eta_{v} \phi}{\left(\mu_{v}+u_{4}\right)\left(u_{3}+\eta_{v}+\mu_{A}\right)}>1, \\
& R_{2}=\frac{\mu_{h} u_{2}}{\mu_{h}+\theta_{h}}<1 .
\end{aligned}
$$

DFE-1 will be locally asymptotically stable if and only if

$$
\begin{aligned}
& \frac{\eta_{v} \phi}{\left(\mu_{v}+u_{4}\right)\left(u_{3}+\eta_{v}+\mu_{A}\right)}=R_{1}>1, \\
& \frac{b^{2} \beta_{v} u_{5} k \beta_{h} A_{h}\left(u_{1} \xi+\mu_{h}+\theta_{h}+\left(\mu_{h}+\theta_{h}\right)(\xi-1) R_{2}\right)\left(R_{1}-1\right)}{\phi\left(\mu_{v}+u_{4}\right)^{2}\left(\gamma_{h}+\mu_{h}\right) N_{h} \mu_{h}\left(\mu_{h}+u_{1}+\theta_{h}\right)} \\
& =\mathscr{R}_{0}<1 .
\end{aligned}
$$

Based on (8), it is known that

1. if $R_{1}<1$, then $\mathscr{R}_{0}<0$ will be obtained;

2. if $R_{1}>1$, then $\mathscr{R}_{0} \in(0,1)$ or $\mathscr{R}_{0} \in(1, \infty)$ will be obtained.

3.2.2. Disease-Free Equilibrium II (DFE-2) Point. This equilibrium is given by

$$
\begin{aligned}
S_{h}^{3} & =\frac{A_{h}}{\mu_{h}}, \\
V_{h}^{3} & =0, \\
\operatorname{In}_{h}^{3} & =0, \\
R_{h}^{3} & =0,
\end{aligned}
$$




$$
\begin{aligned}
A_{v}^{3} & =u_{5} k N_{h}\left(R_{1}-1\right), \\
S_{v}^{3} & =\frac{u_{5} k N_{h} \eta_{v}\left(R_{1}-1\right)}{\mu_{v}+u_{4}}, \\
\operatorname{In}_{v}^{3} & =0,
\end{aligned}
$$

which only exist if and only if

$$
R_{1}=\frac{\eta_{v} \phi}{\left(\mu_{v}+u_{4}\right)\left(u_{3}+\eta_{v}+\mu_{A}\right)}>1
$$

To guarantee the local stability of equilibrium, it is necessary

$$
\begin{aligned}
& \frac{A_{h} \beta_{h} \beta_{v} b^{2} k u_{5} \phi \eta_{v}}{\left(\mu_{h} N_{h}\left(\mu_{v}+u_{4}\right)\left(\mu_{h}+\gamma_{h}\right) \phi+b^{2} u_{5} \beta_{h} \beta_{v} k A_{h}\left(u_{3}+\mu_{A}+\eta_{v}\right)\right)\left(\mu_{v}+u_{4}\right)}=R_{6}<1, \\
& \frac{\eta_{v} \phi}{\left(\mu_{v}+u_{4}\right)\left(u_{3}+\eta_{v}+\mu_{A}\right)}=R_{1}>1 .
\end{aligned}
$$

3.3. Endemic Equilibrium (EE). Endemic equilibrium describes a condition where all compartments, both human and mosquitoes, achieve coexistence. The endemic equilibrium point of system (1) is not in simple way to be written in explicit form. However, the existence of this equilibrium point might be written as equilibrium points that depend on values of $\operatorname{In}_{v}$ and $\operatorname{In}_{h}$ which are given by

$$
\begin{aligned}
S_{h}^{*} & =\frac{\left(\operatorname{In}_{h}^{*} \operatorname{In}_{v}^{*} b \beta_{h} \xi+\mu_{h} \operatorname{In}_{h}^{*} N_{h}\left(\theta_{h}+\mu_{h}\right)\right)\left(\mu_{h}+\gamma_{h}\right)-N_{h}\left(b \beta_{h} A_{h} u_{2} \xi \operatorname{In}_{v}^{*}\right)}{\left(N_{h} \xi u_{1}+b \beta_{h} \operatorname{In}_{v}^{*} \xi+N_{h} \mu_{h}+N_{h} \theta_{h}\right) b \beta_{h} \operatorname{In}_{v}^{*}}, \\
V_{h}^{*} & =\frac{N_{h}\left(u_{2} A_{h} b \beta_{h} \operatorname{In}_{v}^{*}+u_{1} N_{h} \gamma_{h} \operatorname{In}_{h}^{*}+u_{1} N_{h} \mu_{h} \operatorname{In}_{h}^{*}\right)}{\left(N_{h} \xi u_{1}+b \beta_{h} \operatorname{In}_{v}^{*} \xi+N_{h} \mu_{h}+N_{h} \theta_{h}\right) b \beta_{h} \operatorname{In}_{v}^{*}}, \\
R_{h}^{*} & =\frac{\gamma_{h} \operatorname{In}_{h}^{*}}{\mu_{h}+\delta_{h}}, \\
A_{v}^{*} & =\frac{\operatorname{In}_{v}^{*}\left(\mu_{v}+u_{4}\right)\left(N_{h} u_{4}+N_{h} \mu_{v}+b \beta_{v} \operatorname{In}_{h}^{*}\right)}{\eta_{v} b \beta_{v} \operatorname{In}_{h}^{*}}, \\
S_{v}^{*} & =\frac{\operatorname{In}_{v}^{*} N_{h}\left(\mu_{h}+u_{4}\right)}{b \beta_{v} \operatorname{In}_{h}^{*}},
\end{aligned}
$$

while $\operatorname{In}_{v}^{*}$ and $\operatorname{In}_{h}^{*}$ are taken from positive solution of

$$
\begin{aligned}
F_{1} & =\left(b \beta_{v} \operatorname{In}_{h}^{*}+\mu_{v} N_{h}+u_{4} N_{h}\right)\left(b \beta_{v} \operatorname{In}_{h}^{*} \phi u_{5} k N_{h} \eta_{v}\right. \\
& \left.-\left(m u_{v}+u_{4}\right)\right)\left(b k \operatorname{In}_{h}^{*} N_{h} \beta_{v} \eta_{v} u_{5}+b k \operatorname{In}_{h}^{*} N_{h} \beta_{v} \mu_{A} u_{5}\right. \\
& +b k \operatorname{In}_{h}^{*} N_{h} \beta_{v} u_{3} u_{5}+b \phi \operatorname{In}_{h}^{*} \operatorname{In}_{v}^{*} \beta_{v} \\
& \left.+\phi \operatorname{In}_{v}^{*} N_{h}\left(\mu_{v}+u_{4}\right)\right)=0, \\
F_{2} & =\left(A \operatorname{In}_{v}^{2}+B \operatorname{In}_{h}+C\right) \operatorname{In}_{h}+D \operatorname{In}_{v}^{2}+E \operatorname{In}_{v},
\end{aligned}
$$

with

$$
\begin{aligned}
A= & -b^{2} \xi \beta_{h}{ }^{2} \mu_{h}\left(\delta_{h}+\gamma_{h}+\mu_{h}\right), \\
B= & -b N_{h} \beta_{h} \mu_{h}\left(\xi \delta_{h} \gamma_{h}+\xi \delta_{h} \mu_{h}+\xi \delta_{h} u_{1}+\xi \gamma_{h} \mu_{h}\right. \\
& +\xi \gamma_{h} u_{1}+\xi \mu_{h}{ }^{2}+\xi \mu_{h} u_{1}+\delta_{h} \mu_{h}+\delta_{h} \theta_{h}+\gamma_{h} \mu_{h} \\
& \left.+\gamma_{h} \theta_{h}+\mu_{h}{ }^{2}+\mu_{h} \theta_{h}\right),
\end{aligned}
$$

$$
\begin{aligned}
C & =-N_{h}{ }^{2} \mu_{h}\left(\mu_{h}+\theta_{h}+u_{1}\right)\left(\mu_{h}+\gamma_{h}\right)\left(\delta_{h}+\mu_{h}\right), \\
D & =b^{2} \xi A_{h} \beta_{h}{ }^{2}\left(\delta_{h}+\mu_{h}\right), \\
E & =b A_{h} N_{h} \beta_{h}\left(\xi \mu_{h} u_{2}+\xi u_{1}-\mu_{h} u_{2}+\mu_{h}+\theta_{h}\right)\left(\delta_{h}\right. \\
& \left.+\mu_{h}\right) .
\end{aligned}
$$

Substituting all parameters values from Table 1 into above couple of equations will give us existence of $\operatorname{In}_{v}$ and $\operatorname{In}_{h}$ numerically as shown in Figure 2. It can be seen that, as long as the intersection between $F_{1}$ and $F_{2}$ is in the first quadrant, we will have a positive endemic equilibrium.

For simple case when no intervention is given into system (1) $\left(u_{1}=u_{2}=u_{3}=u_{4}=0\right.$ and $\left.u_{5}=1\right)$, endemic equilibrium point is given by

$$
\left(S_{h}^{+}, V_{h}^{+}, \operatorname{In}_{h}^{+}, R_{h}^{+}, A_{v}^{+}, S_{v}^{+}, \operatorname{In}_{v}^{+}\right),
$$


TABLE 1: Parameters values.

\begin{tabular}{lcl}
\hline Parameters & Value & Description \\
\hline$N_{h}$ & 1000 & Total of human population is assumed to be 1000 people. \\
$\mu_{h}$ & $1 /(65 \times 365)$ & Since human life expectation is approximately 65 years, we have $\mu_{h}=1 /(65 \times 365)[23]$. \\
$A_{h}$ & $1000 /(65 \times$ & Since in our model the total of the human population is constant, we have $A_{h}=N_{h} \mu_{h}=1000 /(65 \times 365)$. \\
$\phi$ & $365)$ & We assume that each female Aedes aegypti produces 300 eggs at each spawning. \\
$\beta_{h}, \beta_{v}$ & 300 & It is assumed that it needs 10 successful contacts to infect a human/mosquito with dengue [23]. \\
$\theta_{h}$ & 0,1 & We assume that the effect of vaccination will have disappeared in 60 days. \\
$\gamma_{h}$ & $1 / 60$ & The natural recovery rate for the human population from dengue is 14 days [4]. \\
$\xi$ & $1 / 14$ & With vaccination, the infection rate from mosquito to human population will be reduced by 90\%. \\
$\mu_{v}$ & 0.1 & Life expectation of the mosquito population is 30 days [4]. \\
$\mu_{A}$ & $1 / 30$ & We assume that there is only a 25\% chance that larvae might grow and become adult mosquitoes, with \\
$\eta_{v}$ & $0.75 / 21$ & time to transition being 21 days. \\
$\delta_{h}$ & $0.25 / 21$ & Transition from aquatic phase to adult mosquito [4]. \\
$b$ & $1 / 30$ & Short-term immunity of humans to dengue after recovery is 30 days [23]. \\
$k$ & 1 & Mosquitoes only bite once a day [23]. \\
\hline
\end{tabular}

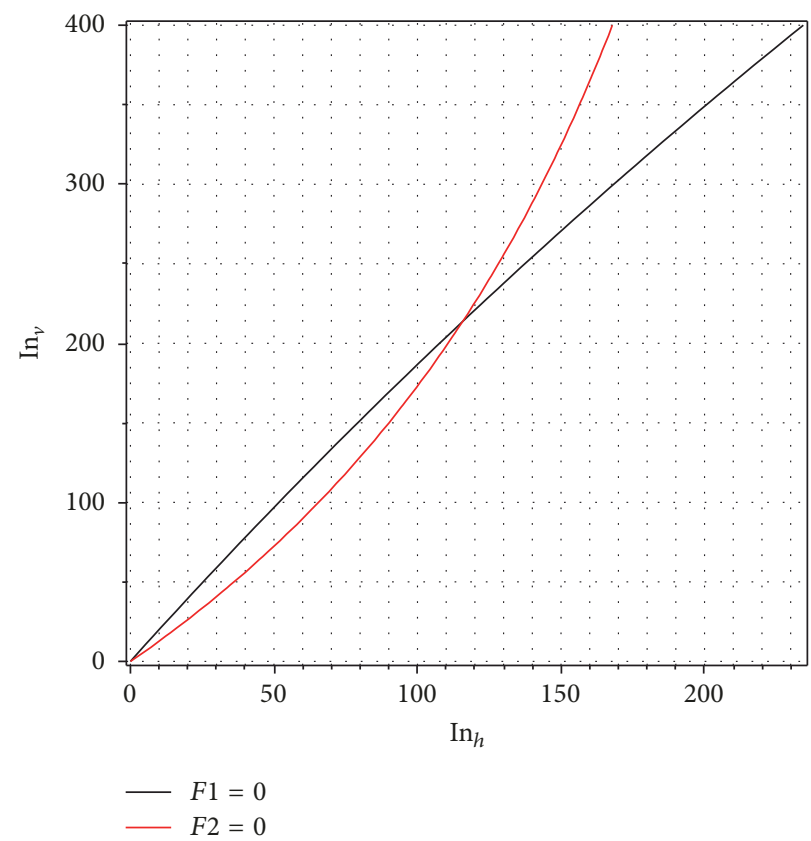

FIGURE 2: Existence of endemic equilibrium for $\operatorname{In}_{v}$ and $\operatorname{In}_{h}$ depending on couple of polynomial characteristics.

where

$$
\begin{aligned}
S_{h}^{+} & =-\frac{\mu_{v}\left(\mu_{h}+\gamma_{h}\right)\left(N_{h} \mu_{h}{ }^{2} \mu_{v}+\left(N_{h} \mu_{v}\left(\delta_{h}+\gamma_{h}\right)+b \beta_{v} A_{h}\right) \mu_{h}+b \beta_{v} A_{h} \delta_{h}\right)}{\left(R_{4}-1\right)\left(\mu_{h}{ }^{2} \mu_{v}+\left(\mu_{v}\left(\delta_{h}+\gamma_{h}\right)+b k \eta_{v} \beta_{h}\right) \mu_{h}+\mu_{v} \delta_{h} \gamma_{h}+b k \eta_{v} \beta_{h}\left(\delta_{h}+\gamma_{h}\right)\right) \mu_{h} \beta_{v} b}, \\
V_{h}^{+} & =0, \\
\operatorname{In}_{h}^{+} & =\frac{b k A_{h} \eta_{v} \beta_{h}\left(R_{3}-1\right)\left(\mu_{h}+\delta_{h}\right)}{\left(R_{4}-1\right) \mu_{h}\left(\mu_{h}{ }^{2} \mu_{v}+\left(\mu_{v}\left(\delta_{h}+\gamma_{h}\right)+b k \eta_{v} \beta_{h}\right) \mu_{h}+\mu_{v} \delta_{h} \gamma_{h}+b k \eta_{v} \beta_{h}\left(\delta_{h}+\gamma_{h}\right)\right)},
\end{aligned}
$$




$$
\begin{aligned}
& R_{h}^{+}=\frac{b k A_{h} \eta_{v} \beta_{h} \gamma_{h}\left(R_{3}-1\right)}{\left(R_{4}-1\right) \mu_{h}\left(\mu_{h}^{2} \mu_{v}+\left(\mu_{v}\left(\delta_{h}+\gamma_{h}\right)+b k \eta_{v} \beta_{h}\right) \mu_{h}+\mu_{v} \delta_{h} \gamma_{h}+b k \eta_{v} \beta_{h}\left(\delta_{h}+\gamma_{h}\right)\right)}, \\
& A_{v}^{+}=-N_{h} k\left(R_{5}-1\right), \\
& S_{v}^{+}=-\frac{\left(R_{4}-1\right)\left(\mu_{h}^{2} \mu_{v}+\left(\mu_{v}\left(\delta_{h}+\gamma_{h}\right)+b k \eta_{v} \beta_{h}\right) \mu_{h}+\mu_{v} \delta_{h} \gamma_{h}+b k \eta_{v} \beta_{h}\left(\delta_{h}+\gamma_{h}\right)\right) \mu_{h} N_{h}^{2}}{\beta_{h}\left(N_{h} \mu_{h}^{2} \mu_{v}+\left(N_{h} \mu_{v}\left(\delta_{h}+\gamma_{h}\right)+b \beta_{v} A_{h}\right) \mu_{h}+b \beta_{v} A_{h} \delta_{h}\right) b}, \\
& \operatorname{In}_{v}^{+}=-\frac{A_{h} N_{h} b \beta_{v} \eta_{v} k\left(R_{3}-1\right)\left(\mu_{h}+\delta_{h}\right)}{\mu_{v}\left(N_{h} \mu_{h}\left(\delta_{h}+\gamma_{h}+\mu_{h}\right) \mu_{v}+b \beta_{v} A_{h}\left(\mu_{h}+\delta_{h}\right)\right)} .
\end{aligned}
$$

It is seen that $S_{h}^{+}, V_{h}^{+}, \operatorname{In}_{h}^{+}, R_{h}^{+}, A_{v}^{+}, S_{v}^{+}$, and $\operatorname{In}_{v}^{+}$points can have either a positive or a negative value. But as in the MFE and DFE case, an equilibrium point has biological meaning only if it has positive values. Therefore, to ensure that the EE point exists, the condition for $S_{h}^{+}, V_{h}^{+}, \operatorname{In}_{h}^{+}, R_{h}^{+}, A_{v}^{+}, S_{v}^{+}$, and $\operatorname{In}_{v}^{+}$which has positive value needs to be made; that is,

$$
\begin{aligned}
& R_{3} \\
& =\frac{\left(\phi N_{h} \mu_{h}\left(\mu_{h}+\gamma_{h}\right) \mu_{v}+b^{2} \beta_{h} \beta_{v} k A_{h}\left(\mu_{A}+\eta_{v}\right)\right) \mu_{v}}{A_{h} b^{2} \beta_{h} \beta_{v} \eta_{v} k \phi} \\
& <1, \\
& R_{4} \\
& =\frac{b \beta_{h} k \mu_{v}\left(\mu_{A}+\eta_{v}\right)\left(\delta_{h}+\gamma_{h}+\mu_{h}\right)}{\left(b \beta_{h} k\left(\delta_{h}+\gamma_{h}+\mu_{h}\right) \eta_{v}+\mu_{v}\left(\mu_{h}+\delta_{h}\right)\left(\mu_{h}+\gamma_{h}\right)\right) \phi} \\
& <1,
\end{aligned}
$$

$$
R_{5}=\frac{\mu_{v}\left(\mu_{A}+\eta_{v}\right)}{\phi \eta_{v}}<1
$$

Numerical simulation, using data parameters in Table 1, is performed to show an example of the stability of endemic equilibrium points. The numerical simulation result of the equilibrium point stability can be seen in Table 2 .

\section{Basic Reproduction Number}

4.1. Construction of Basic Reproduction Number. Basic reproduction number $\left(\mathscr{R}_{0}\right)$ is defined as the expected number of secondary cases from one primary case in a virgin population during the infection period [24]. $\mathscr{R}_{0}$ can be taken from the spectral radius of the next-generation matrix. Please see [25] for further explanation about the construction of the nextgeneration matrix of the compartmental model in various disease models.

According to our model in system (1) and evaluating it at disease-free equilibrium (DFE) in (5), our next-generation matrix is given by

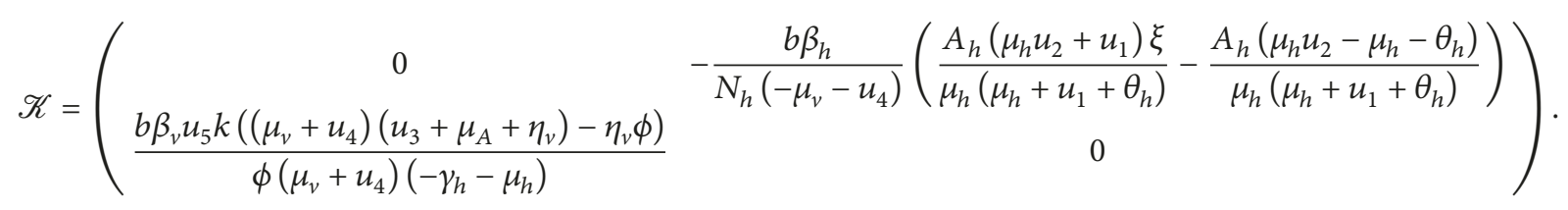

The element of the next-generation matrix $\mathscr{K}$ can be interpreted as follows: the number of new infections in $j$ th column is caused by one infection from $i$ th row of $\mathscr{K}$. Please note that $i$ and $j$ for 1 and 2 represent $\operatorname{In}_{h}$ and $\operatorname{In}_{v}$ group. Therefore, for example, $\mathscr{K}_{2,1}$ represent the case that one infected mosquito will produce $b \beta_{v} u_{5} k\left(\left(\mu_{v}+u_{4}\right)\left(u_{3}+\mu_{A}+\eta_{v}\right)-\eta_{v} \phi\right) / \phi\left(\mu_{v}+\right.$ $\left.u_{4}\right)\left(-\gamma_{h}-\mu_{h}\right)$ number of new infected people. On the other hand, $\mathscr{K}_{1,2}$ represent the case that one infected human will produce $-\left(b \beta_{h} / N_{h}\left(-\mu_{v}-u_{4}\right)\right)\left(A_{h}\left(\mu_{h} u_{2}+u_{1}\right) \xi / \mu_{h}\left(\mu_{h}+u_{1}+\right.\right.$ $\left.\left.\theta_{h}\right)-A_{h}\left(\mu_{h} u_{2}-\mu_{h}-\theta_{h}\right) / \mu_{h}\left(\mu_{h}+u_{1}+\theta_{h}\right)\right)$ number of new infected mosquitos. Supported by dengue facts that the new infection in human and mosquito population cannot occur from contact between human and human or mosquito and mosquito, we have that $\mathscr{K}_{1,1}$ and $\mathscr{K}_{2,2}$ are equal to 0 .
Finding the spectral radius of (18), our basic reproduction number associated with system (1) is given by

$$
\begin{aligned}
& \mathscr{R}_{0} \\
& =\frac{b^{2} \beta_{v} u_{5} k \beta_{h} A_{h}\left(u_{1} \xi+\mu_{h}+\theta_{h}+\left(\mu_{h}+\theta_{h}\right)(\xi-1) R_{2}\right)\left(R_{1}-1\right)}{\phi\left(\mu_{v}+u_{4}\right)^{2}\left(\gamma_{h}+\mu_{h}\right) N_{h} \mu_{h}\left(\mu_{h}+u_{1}+\theta_{h}\right)},
\end{aligned}
$$

with $R_{1}$ and $R_{2}$ already defined in the previous section.

Please note that, according to the previous section, this $\mathscr{R}_{0}$ becomes a threshold number to guarantee the existence and local stability of the disease-free equilibrium point (see (5)) and endemic equilibrium point. We find that the diseasefree equilibrium point will be locally asymptotically stable when $\mathscr{R}_{0}<1$. This situation will tend the system to possibility 
TABLE 2: Numerical example to show existence and stability of equilibrium points for various values of parameters in Table 1 and $u_{1}=0, u_{3}=$ $0, u_{5}=1$.

\begin{tabular}{|c|c|c|c|c|c|c|}
\hline$\phi$ & $u_{4}$ & $u_{2}$ & $\mathscr{R}_{0}$ & $R_{1}$ & $\begin{array}{c}\text { Stable } \\
\text { equilibrium }\end{array}$ & Point \\
\hline 3 & 1 & 0,1 & -0.0012 & 0.7258 & MFE & $\begin{array}{c}\left(S_{h}=999.7477 ; V_{h}=0.25226\right. \\
\operatorname{In}_{h}=0 ; R_{h}=0 ; A_{v}=0 \\
\left.S_{v}=0 ; \operatorname{In}_{v}=0\right)\end{array}$ \\
\hline 300 & 1 & 0,1 & 0.0031 & 72.5807 & DFE-1 & $\begin{array}{c}\left(S_{h}=999.7477 ; V_{h}=0.2522598 ;\right. \\
\operatorname{In}_{h}=0 ; R_{h}=0 ; A_{v}=1972.4444 ; \\
\left.\quad S_{v}=22.7240 ; \operatorname{In}_{v}=0\right)\end{array}$ \\
\hline 300 & 1 & 0 & 0,0031 & 72.5807 & DFE-2 & $\begin{array}{c}\left(S_{h}=1000 ; V_{h}=0 ; \operatorname{In}_{h}=0 ;\right. \\
R_{h}=0 ; A_{v}=1972.444 \\
\left.S_{v}=22.7240 ; \operatorname{In}_{v}=0\right)\end{array}$ \\
\hline 300 & 0 & 0,1 & 2,9962 & 2250,00 & $\mathrm{EE}$ & $\begin{array}{c}\left(S_{h}=494.6757 ; V_{h}=0 ; 2215 ;\right. \\
\operatorname{In}_{h}=160 ; 8530 ; R_{h}=344 ; 2498 ; \\
A_{v}=1999 ; 1111 ; S_{v}=481 ; 5783 ; \\
\left.\quad \operatorname{In}_{v}=232 ; 3899\right)\end{array}$ \\
\hline
\end{tabular}

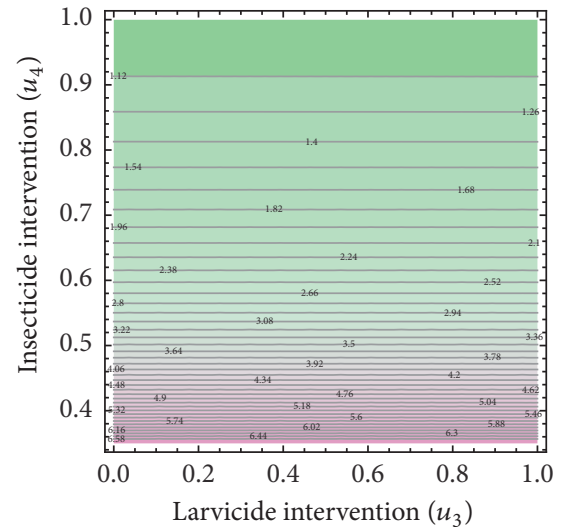

(a)

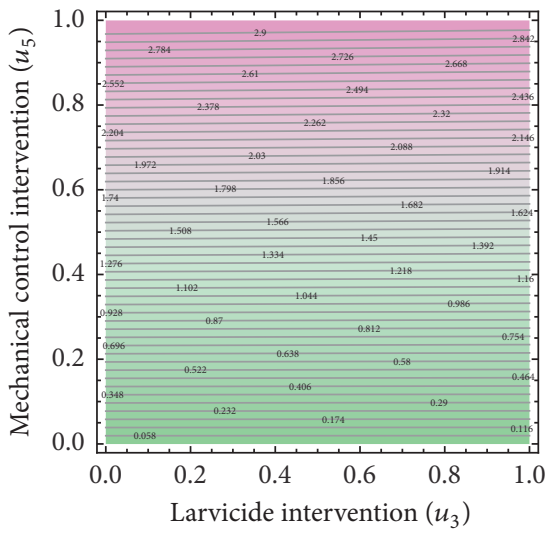

(b)

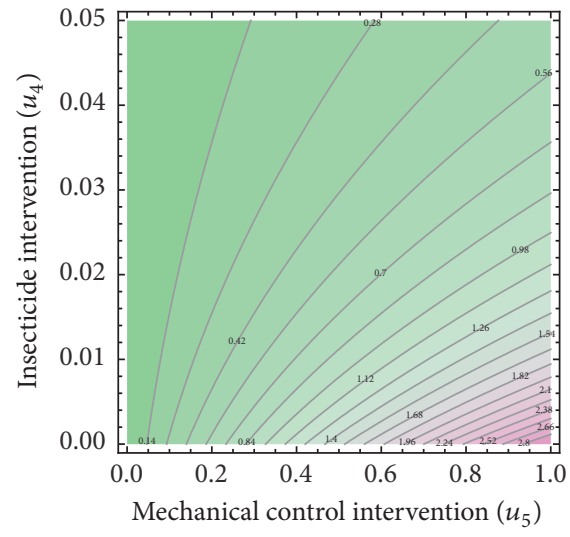

(c)

FIGURE 3: Sensitivity analysis of $\mathscr{R}_{0}$ with respect to dengue intervention in mosquito population.

equilibrium, that is, stable in MFE if $\mathscr{R}_{1}<1$ and stable in DFE if $\mathscr{R}_{1}>1$. On the other hand, if $\mathscr{R}_{0}>1$, the DFE or MFE will be unstable and the system will tend to endemic equilibrium point.

4.2. Sensitivity Analysis of Basic Reproduction Number. In this subsection, a sensitivity analysis of the basic reproduction number will be performed to find and compare the most sensitive parameters $\left(u_{i}\right)$ to determine the value of $\mathscr{R}_{0}$. In the first subsection, we will compare the sensitivity analysis of intervention in the mosquito population $\left(u_{i}\right.$ for $\left.i=3,4,5\right)$ and in the next subsection we will compare the sensitivity of intervention in the human population $\left(u_{i}\right.$ for $\left.i=1,2\right)$.

4.2.1. Sensitivity Analysis in Mosquito Population. As already stated in the previous section, we include larvicide, fumigation, and mechanical control in our model as $u_{3}, u_{4}$, and $u_{5}$, respectively. To find the sensitivity curve of basic reproduction number as shown in Figure 3 for $u_{i}$ and $u_{j}$, we input all parameters into $\mathscr{R}_{0}$ except $u_{i}$ and $u_{j}$ and then plot its implicit equation.

In Figure 3(a), a comparison of the efficacy of larvicide and insecticide is performed and we find that insecticide is much more efficacious in reducing $\mathscr{R}_{0}$ than larvicide. In the next figure, Figure 3(b), we find that intervention using mechanical control is more efficacious in reducing $\mathscr{R}_{0}$. Finally, we compare the efficacy of insecticide and mechanical control, and we find that insecticide is much more efficacious in reducing $\mathscr{R}_{0}$. Therefore, from these three figures, we conclude that insecticide is the best way of controlling dengue spread, followed by mechanical control and larvicide, respectively.

4.2.2. Sensitivity Analysis in Human Population. In this subsection, the same procedure is applied to find the sensitivity of $\mathscr{R}_{0}$ in Figure 4 . It can be seen that the larger the intervention of vaccination we give, the smaller $\mathscr{R}_{0}$ will be, and reducing $\mathscr{R}_{0}$ with intervention of adult vaccination $\left(u_{1}\right)$ is faster than with vaccination of newborns $\left(u_{2}\right)$. 


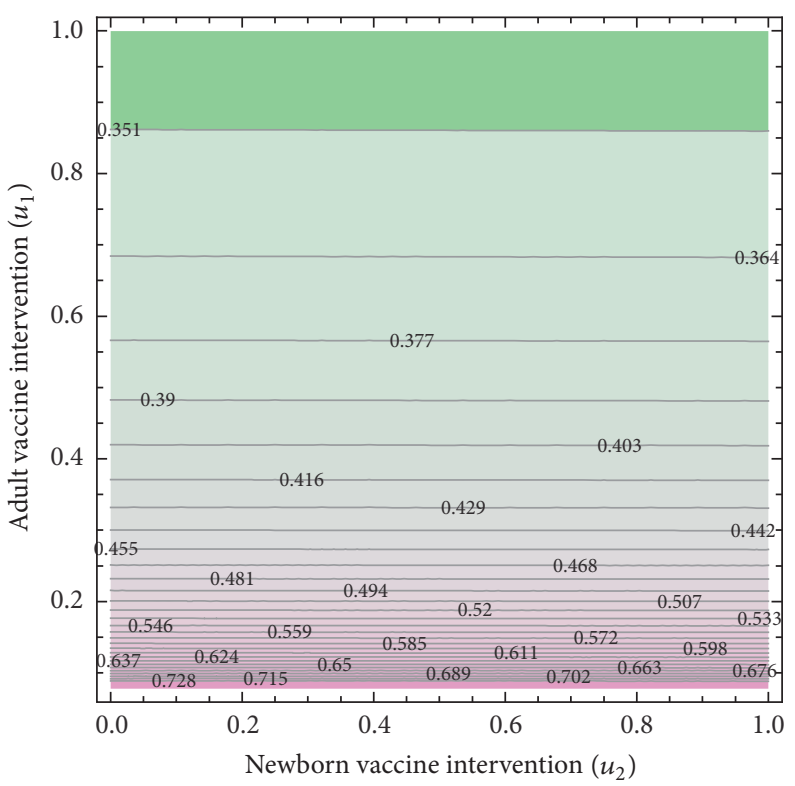

FIGURE 4: Sensitivity analysis of $\mathscr{R}_{0}$ with respect to dengue intervention in human population.

To back up the result given in the two previous figures in Figures 3 and 4, we will determine the value of each intervention in a single-intervention scenario. This means that if we only use vaccination intervention in the model, we will set the other parameters to 0 for $u_{2}, u_{3}, u_{4}$ and 1 for $u_{5}$. With this scenario, we need $u_{1}=0.04765, u_{2}=293.04, u_{3}=$ $71.363, u_{4}=0.02436$, and $u_{5}=0.33364$ to reduce $\mathscr{R}_{0}$ to 0.99 . It can be seen that $u_{4}$ is the smallest value of intervention to reduce $\mathscr{R}_{0}$ with respect to controlling the spread of dengue.

In the next section, we present some numerical experiments to show the long- and short-term behavior of our model in (1) with respect to the value of various interventions.

\section{Numerical Experiment}

To perform a numerical experiment in this section, we use the parameters values given in Table 1 and the initial condition given by

$$
\begin{aligned}
S_{h}(0) & =980 ; \\
V_{h}(0) & =0 ; \\
\operatorname{In}_{h}(0) & =20 ; \\
R_{h}(0) & =0 ; \\
A_{v}(0) & =2000 ; \\
S_{v}(0) & =980 ; \\
\operatorname{In}_{v}(0) & =20 .
\end{aligned}
$$

As it can be seen from (20), total numbers of human $\left(S_{h}+\right.$ $\left.V_{v}+\mathrm{In}_{h}+R_{h}\right)$ and adult mosquito $\left(S_{v}+\operatorname{In}_{v}\right)$ are 1000 in $t=0$. The number of infected humans and mosquitoes is small to describe the situation when the infection of dengue has just started. Using a value of $u_{i}$ in the previous section to reduce $\mathscr{R}_{0}$ to 0.99 , it can be seen that $u_{2}$ and $u_{3}$ will not satisfy the condition that $u_{i}$ should be between 0 and 1 . For the next simulation, therefore, we will only perform the dynamic behavior of infected groups $\left(\operatorname{In}_{h}, \mathrm{In}_{v}\right)$ with respect to intervention of $u_{1}, u_{4}$, and $u_{5}$ as shown in Figures 5 and 6 for $\operatorname{In}_{h}$ and $\operatorname{In}_{v}$, respectively.

Figures 5 and 6 show the dynamic of infected humans and mosquitoes in the short term $(t \in[0,100])$ and long term $(t \in[300,500])$. It can be seen that, without intervention, the number of infected humans and infected mosquitoes will tend to endemic equilibrium, since $\mathscr{R}_{0}=2.99>$ 1. After intervention is given until $\mathscr{R}_{0}=0.99<1$ (we take $u_{1}=0.04765$ or $u_{4}=0.02436$ and $/$ or $u_{5}=$ 0.33364 to represent each simulation), the number of infected humans and mosquitoes will be decreased and pushed to the disease-free equilibrium point. It can also be seen in Figure 5 that intervention of adult vaccination in shortterm simulations is the best way to reduce the number of infected humans to the lowest level, rather than other interventions, following this with fumigation and mechanical control interventions, respectively. Unfortunately, for longterm simulations, intervention by fumigation is the best way to reduce the number of infected humans, rather than an adult vaccination strategy. On the other hand, in both shortand long-term simulations, intervention by fumigation is the best way to reduce the number of infected mosquitoes, as shown in Figure 6.

The next simulation is performed to show the efficacy of $u_{4}$ as the best strategy for long-term intervention in both human and mosquito populations, as shown in Figure 7. It can be seen that an intervention of $u_{4}$ gradually from 0 to 0.1 will reduce $\mathscr{R}_{0}$ from 2.99 to 0.18 . As a consequence, a smaller $\mathscr{R}_{0}$ will reduce the infected population and delay the 


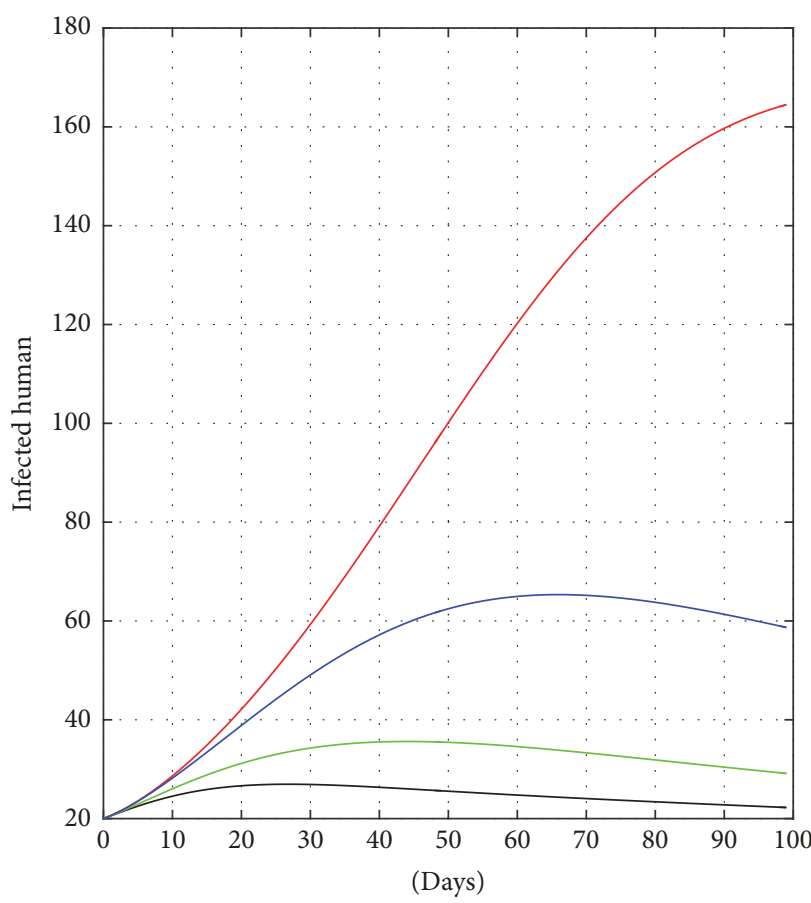

Without intervention $(R 0=2.996898211)$

- Adult vaccination only $(u 1=0.04857655958, R 0=0.99)$

Fumigation only $(u 4=0.02465301004, R 0=0.99)$

- Mechanical control only $(u 5=0.3303415499, R 0=0.99)$

(a)

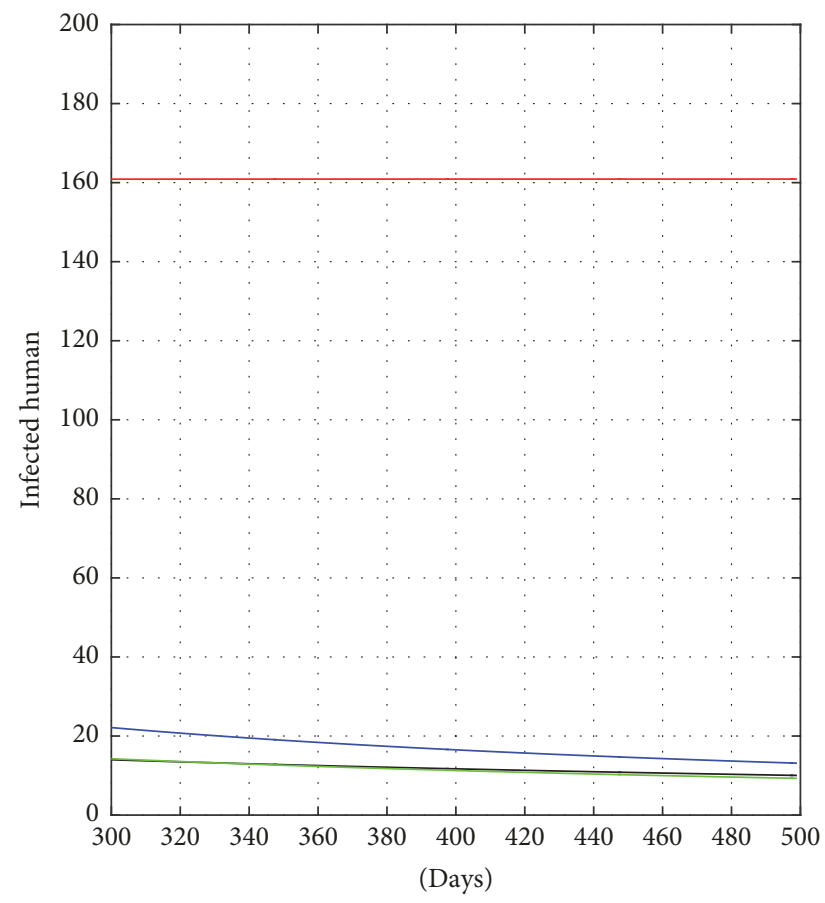

Without intervention $(R 0=2.996898211)$

Adult vaccination only $(u 1=0.04857655958, R 0=0.99)$

Fumigation only $(u 4=0.02465301004, R 0=0.99)$

Mechanical control only $(u 5=0.3303415499, R 0=0.99)$

(b)

FIGURE 5: Dynamic of infected humans for short-term (a) and long-term (b) intervention.

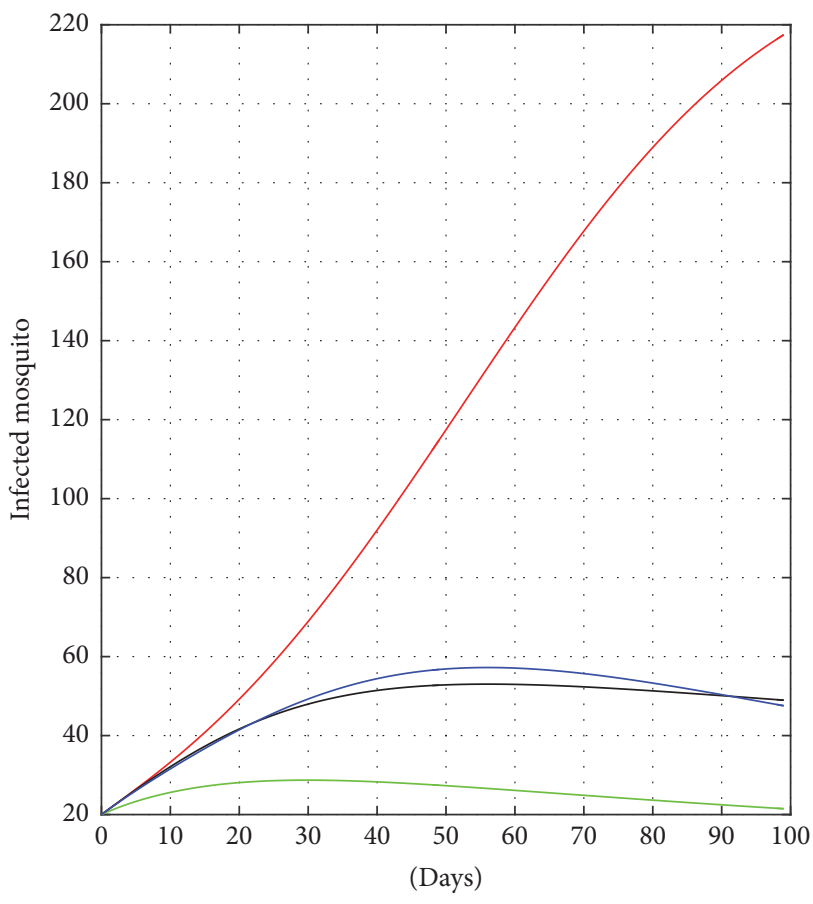

Without intervention $(R 0=2.996898211)$

Adult vaccination only $(u 1=0.04857655958, R 0=0.99)$

Fumigation only $(u 4=0.02465301004, R 0=0.99)$

Mechanical control only $(u 5=0.3303415499, R 0=0.99)$

(a)

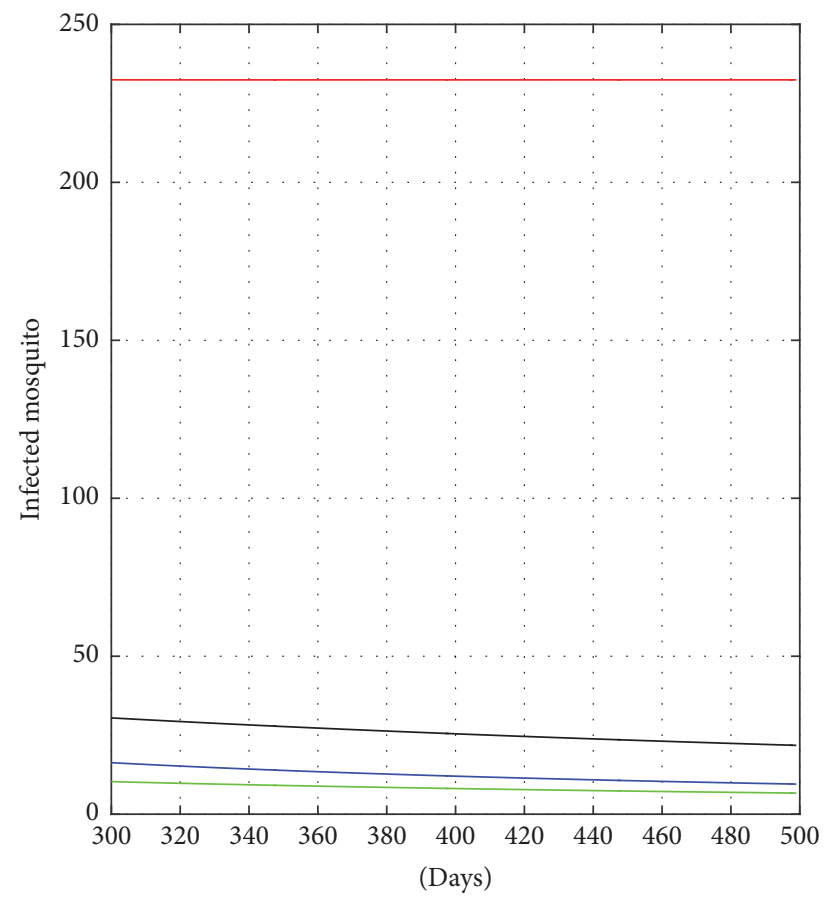

- Without intervention $(R 0=2.996898211)$

Adult vaccination only $(u 1=0.04857655958, R 0=0.99)$

Fumigation only $(u 4=0.02465301004, R 0=0.99)$

- Mechanical control only $(u 5=0.3303415499, R 0=0.99)$

(b)

Figure 6: Dynamic of infected mosquitoes for short-term (a) and long-term (b) intervention. 


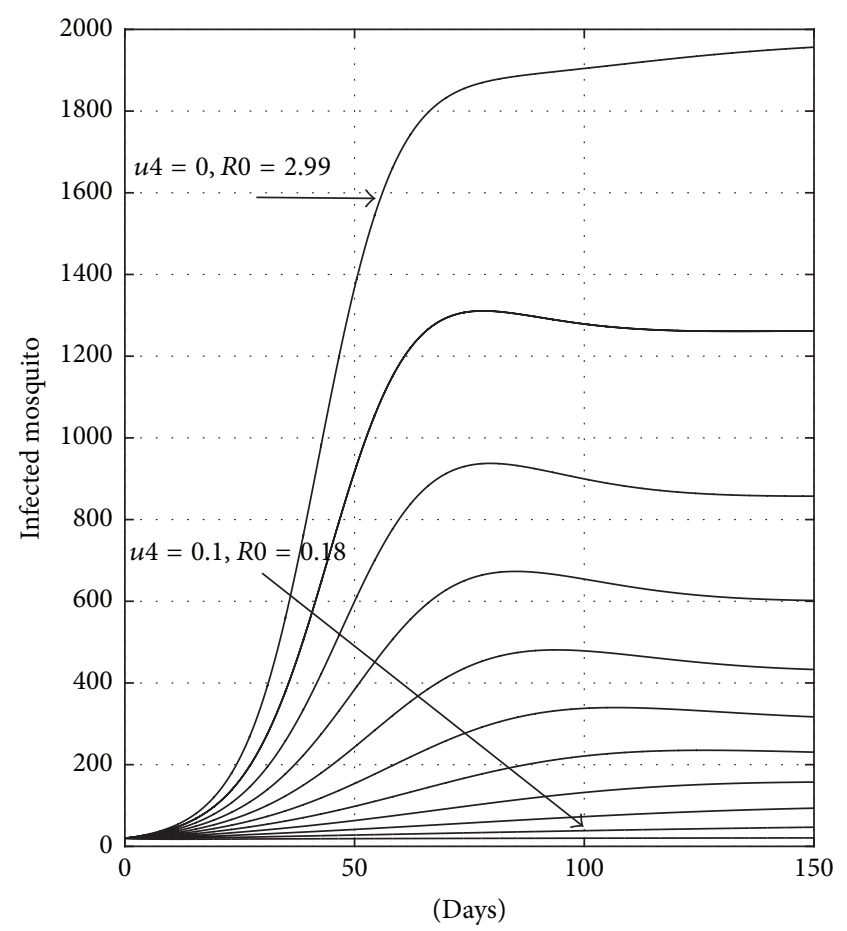

(a)

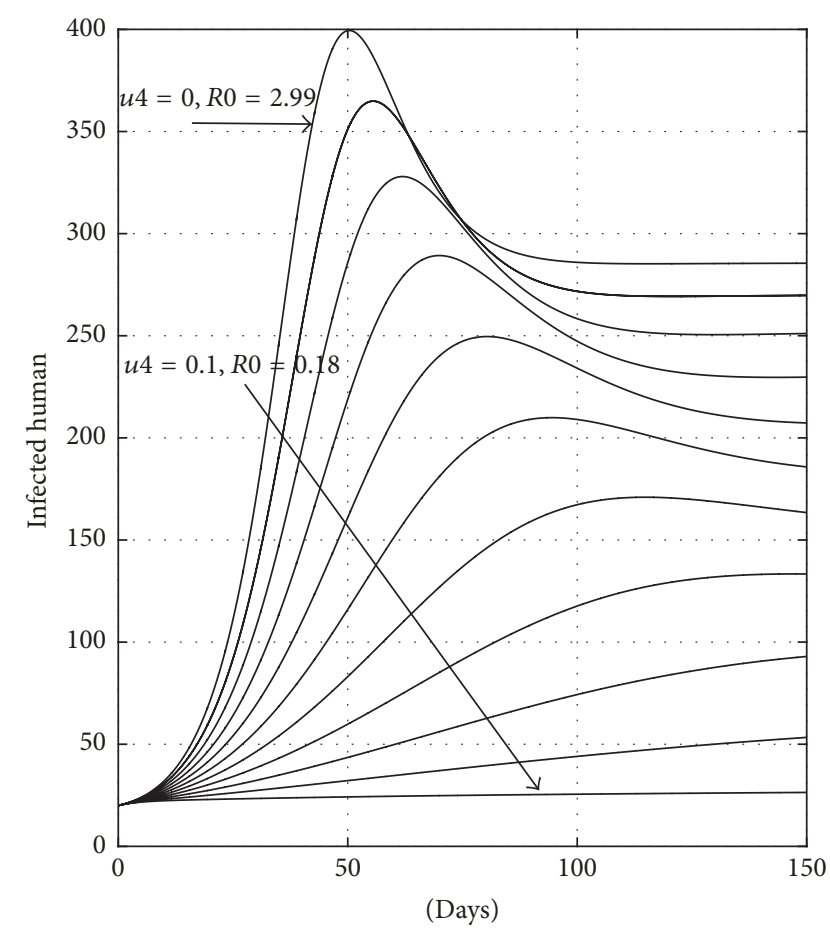

(b)

FIgURE 7: Sensitivity of $u_{4}$ with respect to the number of infected mosquitoes (a) and infected humans (b).

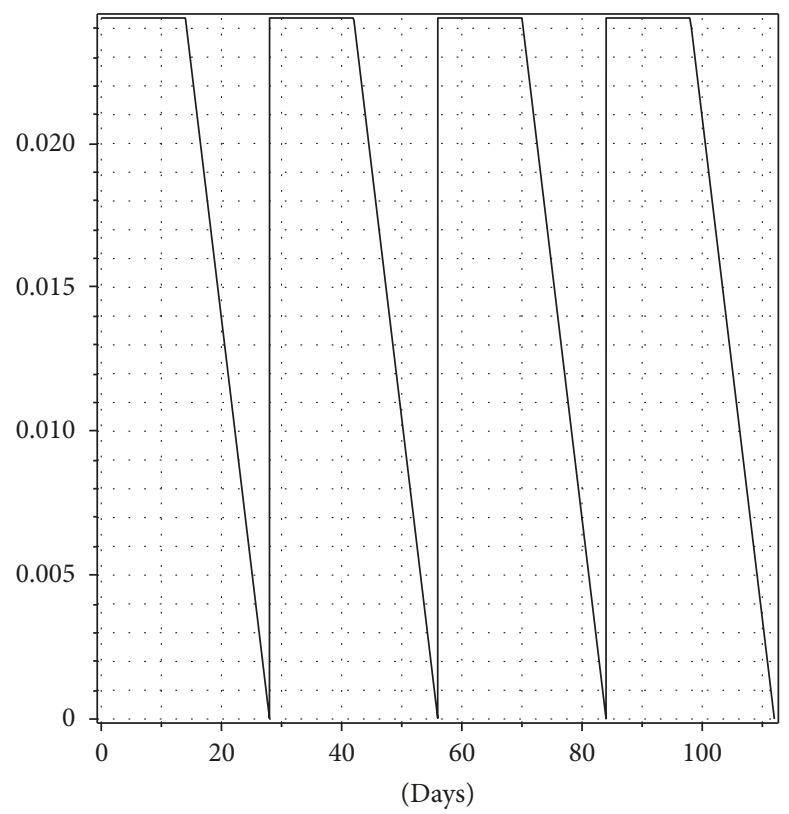

Figure 8: Biweekly fumigation strategy.

outbreak for some time. It can also be seen that it needs a proper value of $u_{4}$ in order that the dynamic of the infected population will never reach outbreak level.

The last simulation is performed to show the effect of periodic as opposed to constant fumigation intervention. For this purpose, the fumigation is implemented biweekly as a constant (0.02436), and the effect of fumigation will disappear linearly after two weeks, as illustrated in Figure 8. As a result, although constant intervention is much better at significantly reducing the number of infected and susceptible mosquitoes in the mosquito population, as shown in Figure 9, biweekly intervention is only slightly different from constant intervention in reducing the number of infected humans and increasing the number of susceptible humans, as shown in 


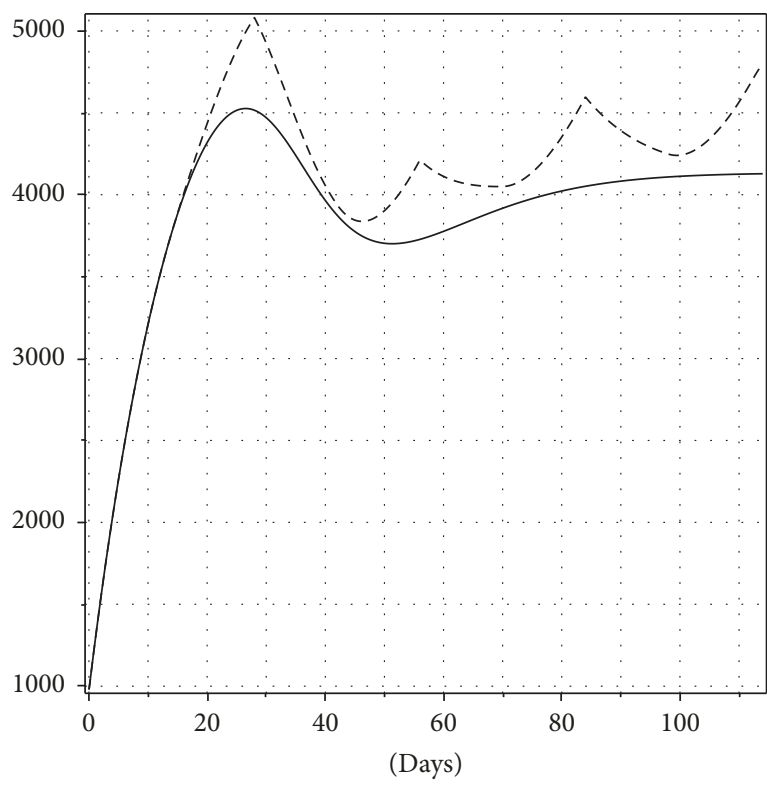

(a)

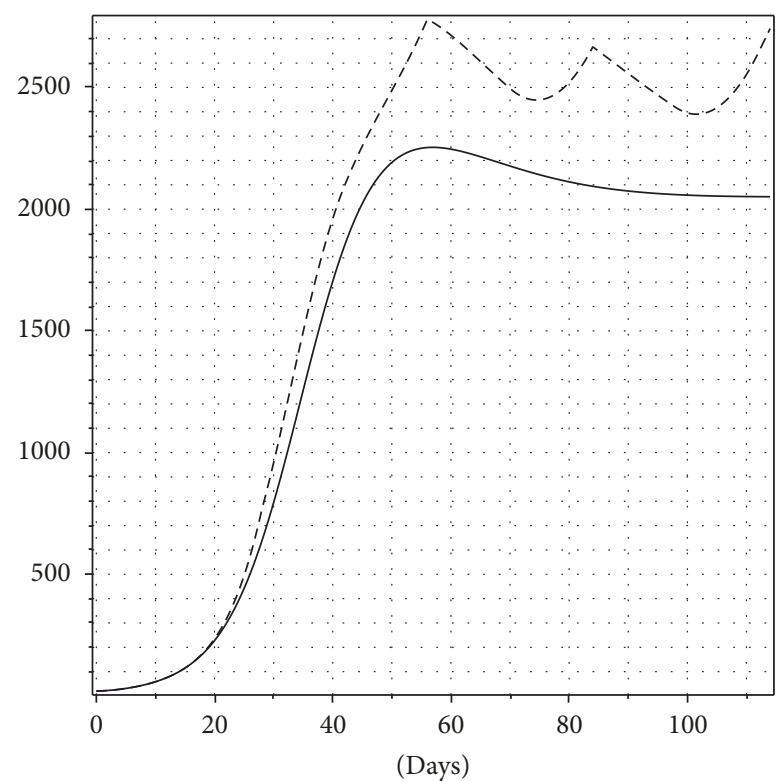

(b)

FIGURE 9: Susceptible (a) and infected (b) mosquito dynamics with constant (solid curve) and biweekly (dash curve) strategy.

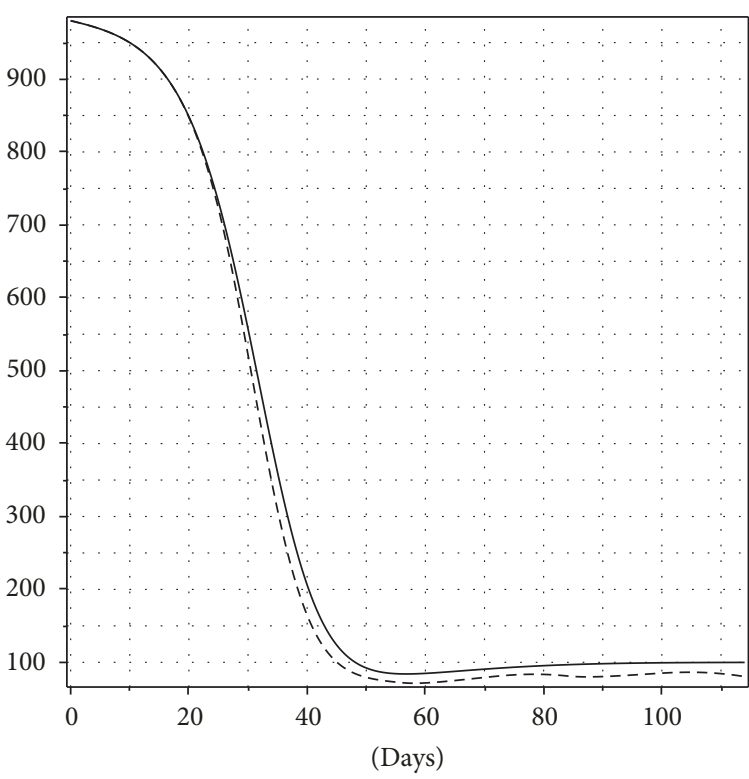

(a)

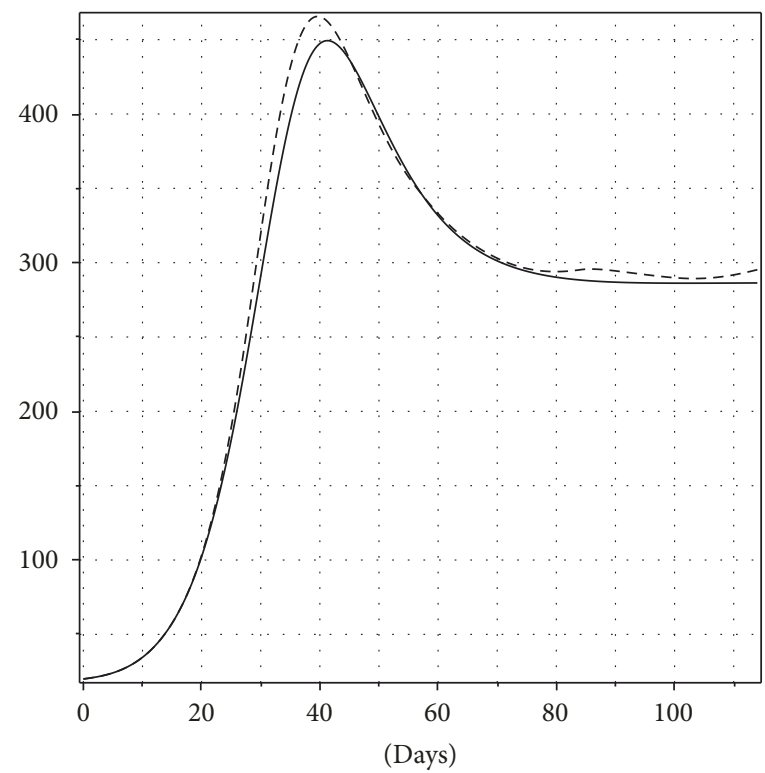

(b)

FIGURE 10: Susceptible (a) and infected (b) human dynamics with constant (solid curve) and biweekly (dash curve) strategy.

Figure 10. This result indicates that, rather than implementing fumigation constantly, which is more expensive, it would be better to implement a fumigation strategy periodically, since it involves a lower cost.

\section{Conclusions}

In this article, we have proposed a mathematical model of dengue spread, with various interventions, such as vaccination of adults and newborns in the human population, and larvicide, insecticide, and mechanical control of the mosquito population. Basic reproduction number and basic offspring as the endemic threshold for disease existence and mosquito existence, respectively, have been shown analytically. We find that disease-free equilibrium will be locally asymptotically stable if, and only if, basic reproduction number is smaller than one and will be unstable otherwise.

From sensitivity analysis and backed up with some numerical simulations, we find that fumigation is the best strategy for long-term intervention to reduce the infected 
populations of both mosquitoes and humans. But for shortterm intervention, vaccination of the adult population is the best way to reduce the number of infected people. From numerical simulation, intervention using fumigation, apart from reducing the outbreak, can also delay an outbreak for some period of time.

We also find that although periodic intervention strategy of fumigation cannot reduce the number of infected humans and mosquitoes as efficiently as constant intervention, it is only slightly different. Therefore, if the government has a limited budget, then periodic intervention could be a good option to implement.

For future research, reconstructing the model in this article as an optimal control problem will be considered to show the effectiveness of interventions, not only based on a reduction of the number of infected humans and mosquitoes but also with the lowest cost for intervention purposes.

\section{Conflicts of Interest}

The authors declare that they have no conflicts of interest.

\section{Acknowledgments}

This research is funded by Ministry of Research and Higher Education (Kemenristek Dikti), with PUPT research grant, 2017.

\section{References}

[1] World Health Organization, Dengue: Guidelines For Diagnosis, Treatment, Prevention and Control, World Health Organization. ISBN 9789241547871, 2009.

[2] Education Nature, Dengue Transmission 2016. http://www .nature.com/scitable/topicpage/dengue-transmission-22399758.

[3] H. S. Rodrigues, M. T. T. Monteiro, and D. F. M. Torres, Vaccination models and optimal control strategies to Dengue, Universidade de Aveiro Departamento de Matematica, Portugal, 2013.

[4] D. Aldila, N. Nuraini, and E. Soewono, "Mathematical Model in Controlling Dengue Transmission with Sterile Mosquito Strategies," in Proceedings of the AIP Conference, Indonesia, 2015.

[5] R. I. Kementrian Kesehatan, "Demam Berdarah Dengue," Buletin Jendela Epidemiologi, vol. 2, pp. 11-14, August 2010.

[6] O. A. Aguirre-Obando, A. J. Pietrobon, A. C. D. Bona, and M. A. Navarro-Silva, "Contrasting patterns of insecticide resistance and knockdown resistance (kdr) in Aedes aegypti populations from Jacarezinho (Brazil) after a Dengue Outbreak," Revista Brasileira de Entomologia, vol. 60, no. 1, pp. 94-100, 2016.

[7] K. C. Mulyatno, A. Yamanaka, Ngadino, and E. Konishi, "Resistance of Aedes aegypti (L.) larvae to temephos in Surabaya, Indonesia," Southeast Asian Journal of Tropical Medicine and Public Health, vol. 43, no. 1, pp. 29-33, 2012.

[8] R. Deming, "Spatial Variation of Insecticide Resistance In The Dengue Vector Aedes aegypti Presents Unique Vector Control Challenges," Parasites \& Vectors, vol. 9, no. 67, 2016.

[9] World Health Organization, WHO Global Malaria Programme: World Malaria Report, World Health Organization, Geneva, Switzerland, 2013.
[10] G. Olivera, N. Baurin, and L. Coudeville, "The Role Of Indirect Protection In The Assessment Of Dengue Vaccination Impact," in Seventh Workshop Dynamical Systems Applied to Biology andNatural Sciences, Evora, Portugal, 2016.

[11] S. Pasteur, "First Dengue Vaccine, Dengvaxia, Awarded the Vaccine Breakthrough Of 2016 at the 6th Annual Biopharma Industry Awards Event in Singapore," 2016, http://www.dengue .info/\# overlay=content/first-dengue-vaccine-awarded-vaccinebreakthrough-2016-singapore-0.

[12] H. Harapan, S. Anwar, A. M. Setiawan, and R. T. Sasmono, "Dengue vaccine acceptance and associated factors in Indonesia: A community-based cross-sectional survey in Aceh," Vaccine, vol. 34, no. 32, pp. 3670-3675, 2016.

[13] J. Lee, V. Mogasale, J. K. Lim et al., "A Multi-country Study of the Household Willingness-to-Pay for Dengue Vaccines: Household Surveys in Vietnam, Thailand, and Colombia," PLOS Neglected Tropical Diseases, vol. 9, no. 6, p. e0003810, 2015.

[14] T. Wahyuni, "Berantas DBD dengan Jumatik dan Vaksin Dengvaxia," CNN Indonesia, 2016, http://www.cnnindonesia.com/ gaya-hidup/20160112181200-255-103823/berantas-dbd-denganjumantik-dan-vaksin-dengvaxia/.

[15] L. Esteva and C. Vargas, "Analysis of a dengue disease transmission model," Mathematical Biosciences, vol. 150, no. 2, pp. 131$151,1998$.

[16] Z. Feng and J. X. Velasco-Hernandez, "Competitive exclusion in a vector-host model for the dengue fever," Journal of Mathematical Biology, vol. 35, no. 5, pp. 523-544, 1997.

[17] N. T. J. Bailey, The Mathematical Theory of Infectious Diseases and its Application, Griffin, London, UK, 1975.

[18] K. Dietz, "Transmission and control of arbovirus diseases," in Proceedings of the Society for Industrial and Applied Mathematics, D. Ludwig et al., Ed., p. 104, Philadelphia, PA, USA, 1974.

[19] H. S. Rodrigues, M. T. Monteiro, D. F. Torres, and A. Zinober, "Dengue disease, basic reproduction number and control," International Journal of Computer Mathematics, vol. 89, no. 3, pp. 334-346, 2012.

[20] H. S. Rodrigues, M. T. T. Monteiro, and D. F. M Torres, "Modeling and Optimal Control Applied to a Vector Borne Disease," in Computational and Mathematical Methods in Science and Engineering (CMMSE) 2012, J. Vigo-Aguiar, Ed., vol. 3, pp. 1063 1070, Murcia, Spain, July 2012.

[21] D. Aldila, N. Nuraini, E. Soewono, and A. K. Supriatna, "Mathematical Model of Temephos Resistance in Aedes aegypti Mosquito Population," in Proceedings of theAIP Conference, 2013.

[22] A. K. Supriatna, E. Soewono, and S. A. van Gils, "A two-ageclasses dengue transmission model," Mathematical Biosciences, vol. 216, no. 1, pp. 114-121, 2008.

[23] D. Aldila, T. Götz, and E. Soewono, "An optimal control problem arising from a dengue disease transmission model," Mathematical Biosciences, vol. 242, no. 1, pp. 9-16, 2013.

[24] O. Diekmann and J. A. P. Heesterbeek, Mathematical Epidemiology of Infectious Diseases, Model Building, Analysis and Interpretation, John Wiley \& Sons, Chichester, UK, 2000.

[25] O. Diekmann, J. A. P. Heesterbeek, and M. G. Roberts, “The construction of next-generation matrices for compartmental epidemic models," Journal of the Royal Society Interface, vol. 7, no. 47 , pp. 873-885, 2010. 


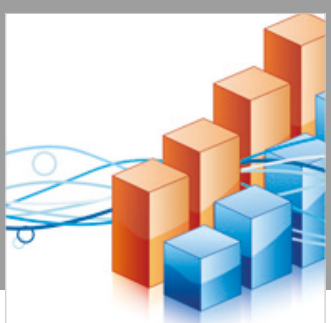

Advances in

Operations Research

\section{-n-m}
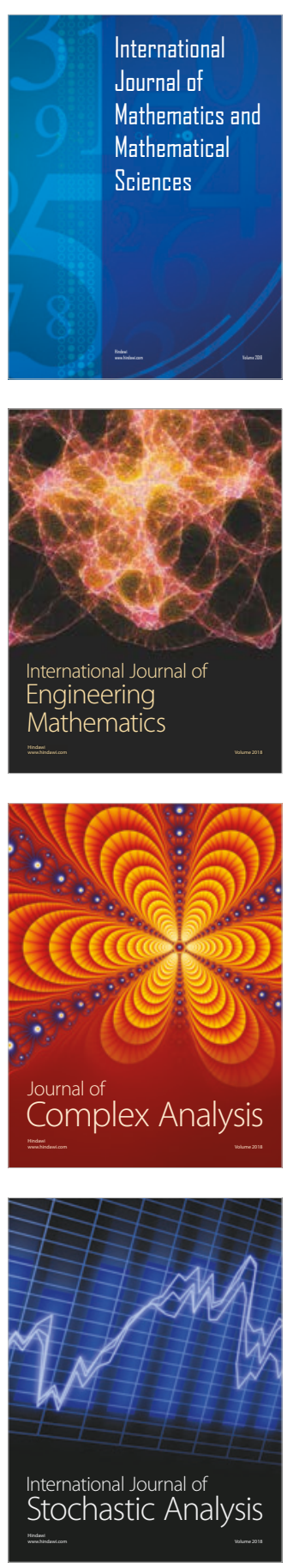
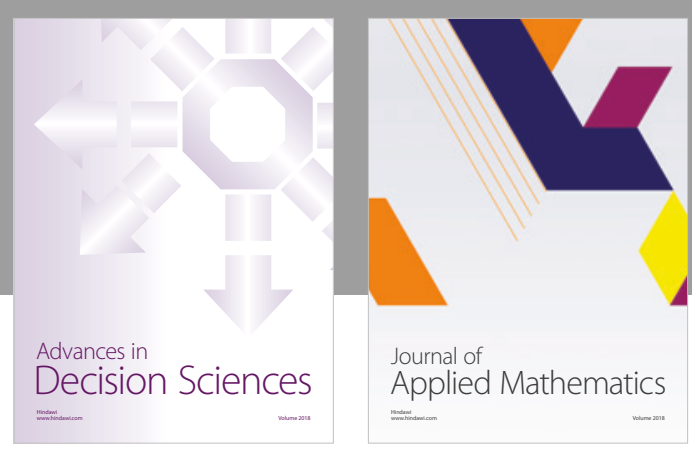

Journal of

Applied Mathematics
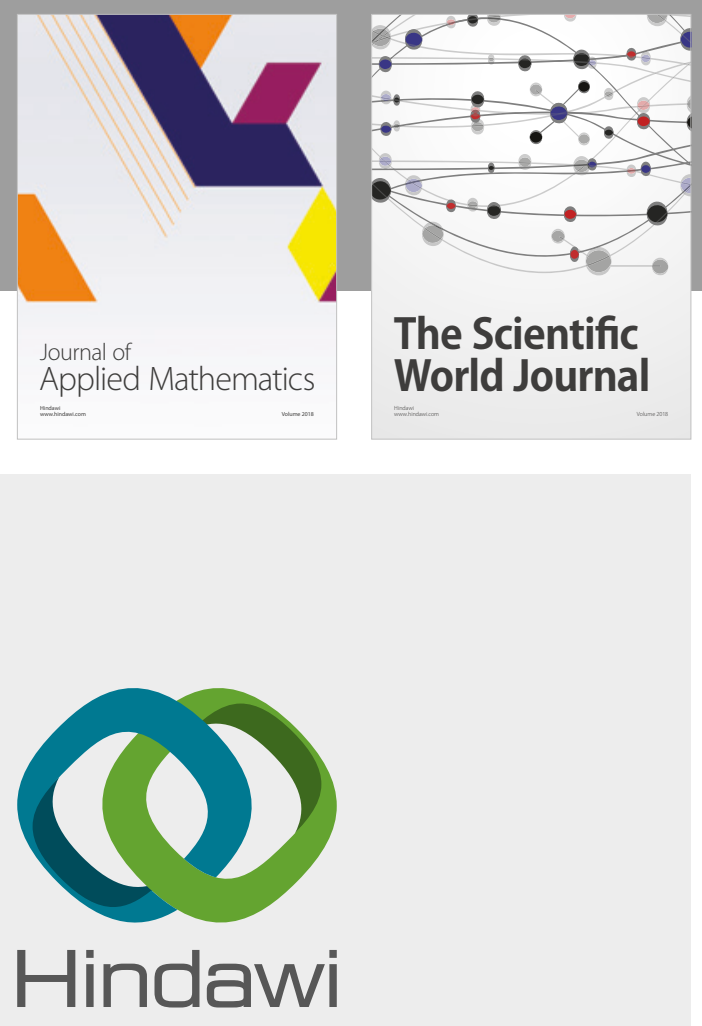

Submit your manuscripts at

www.hindawi.com

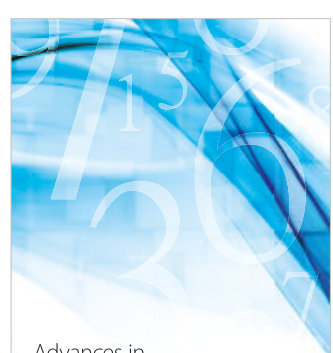

Advances in
Numerical Analysis
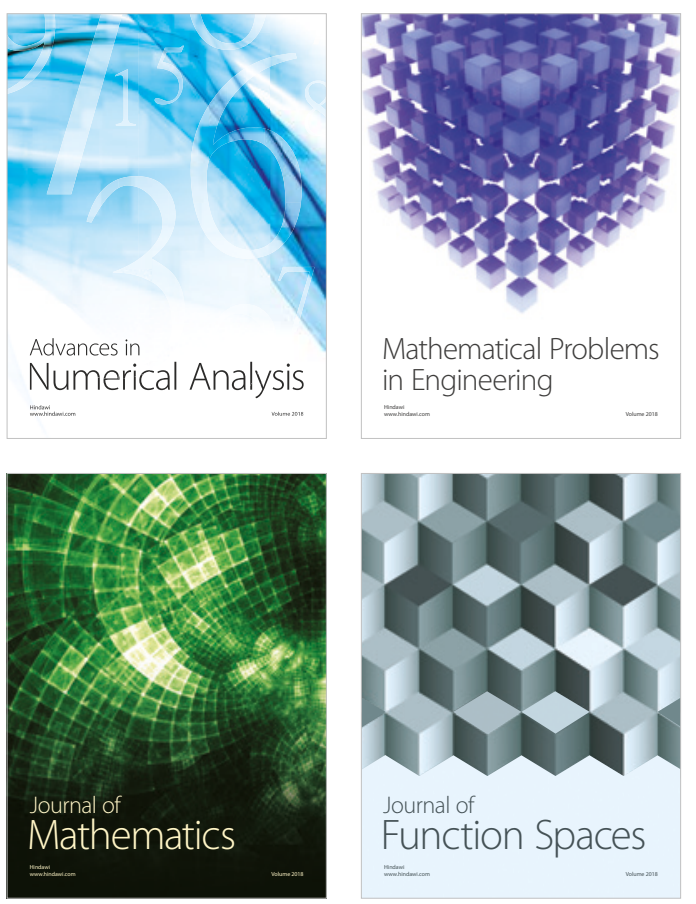

Mathematical Problems in Engineering

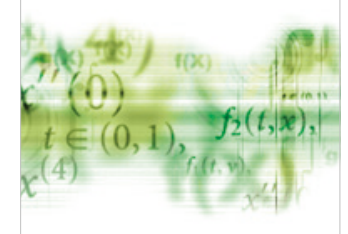

International Journal of

Differential Equations

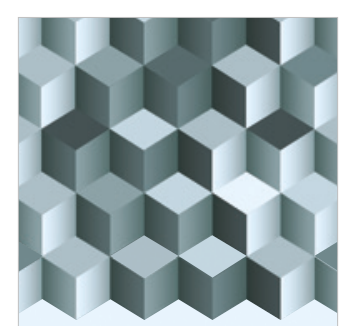

Journal of

Function Spaces

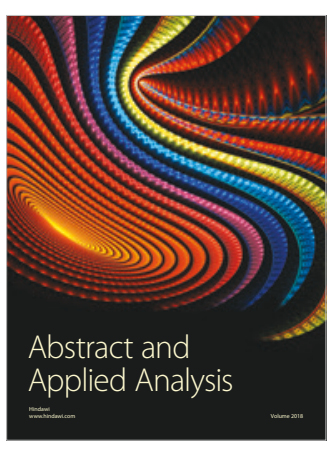

The Scientific

World Journal

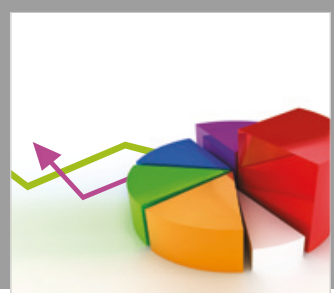

Journal of

Probability and Statistics
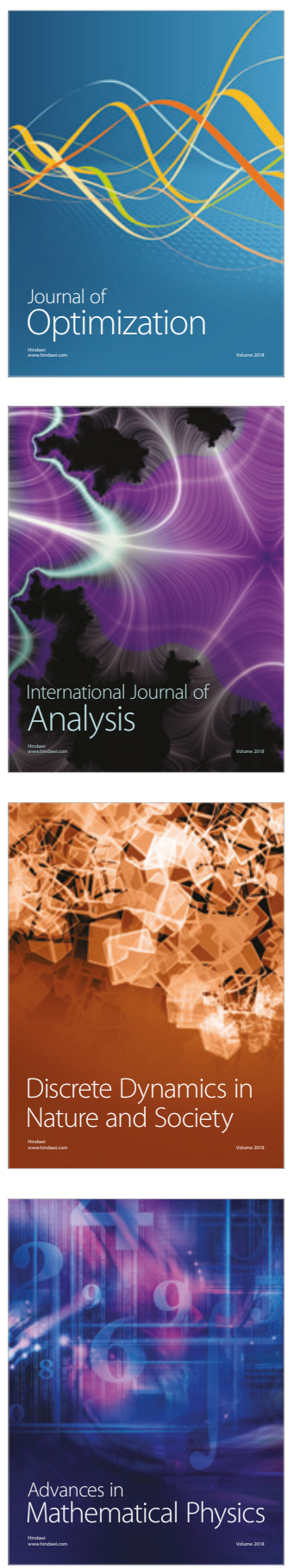